\title{
Performance of Mechanical and Biological Mitral Prostheses in Young Rheumatics Aged Below 45 Years
}

Lakshmi Kumari Sankhyan ${ }^{1}$, Ujjwal Kumar Chowdhury ${ }^{*}$, Diplomate NB ${ }^{2}$, Niwin George ${ }^{2}$, Sushamagayatri B ${ }^{2}$, Srikant Sharma, Diplomate $\mathrm{NB}^{2}$, Sai Divya Yadavalli², Devanish $\mathrm{KNH}^{2}$, Maroof A. Khan²,

${ }^{1}$ All India Institute of Medical Sciences, Bilaspur, Himachal Pradesh

${ }^{2}$ All India Institute of Medical Sciences, New Delhi

*Corresponding Author: Ujjwal Kumar Chowdhury, MCh, Diplomate NB Professor Department of CTVS AIIMS, New Delhi-110029, INDIA

Received Date: February 11, 2021; Accepted Date: March 29, 2021; Published Date: April 02,2021

Citation: Lakshmi K. Sankhyan., Ujjwal K. Chowdhury., Diplomate NB, Niwin George, Sushamagayatri B, et al. (2021) Performance of Mechanical and Biological Mitral Prostheses in Young Rheumatics Aged Below 45 Years. J. Clinical Cardiology and Cardiovascular Interventions, 4(7); Doi:10.31579/2641-0419/149

Copyright: () 2021 Ujjwal Kumar Chowdhury, This is an open-access article distributed under the terms of the Creative Commons Attribution License, which permits unrestricted use, distribution, and reproduction in any medium, provided the original author and source are credited.

\section{Abstract}

Background and Aim: We compared 22-year composites of valve-related reoperation, morbidity, and mortality following mitral mechanical and bioprostheses in young rheumatics aged <45years.

Methods: Retrospective comparative analysis of valve-related reoperations and survival data were performed from 466 consecutive propensity matched patients undergoing either bioprosthetic MVR (Group I, n=233) or mechanical MVR (Group II, $\mathrm{n}=233$ ) between 1998 and 2019.

Results: The median age was 33 (IQR: 27-40) and 34 (IQR: 28-39) years for Group I and II respectively. The mean followup was 3278.9 patient-years in the biological arm and 3384.4 patient-years in mechanical arm. Bioprosthetic arm exhibited lesser cumulative mortality $(4.5 \%$ vs $9.9 \%, \mathrm{SMD}=-0.04, \mathrm{p}=0.65)$. Hazard regression for mortality included (HR, 95\% CI) preoperative congestive heart failure (CHF) 11.44 (8.44, 624.9), $\mathrm{p}<0.0001$; renal failure 19.51 (8.04, 47.35), $\mathrm{p}<0.0001$; previous operation 6.84 (2.48, 18.84), p<0.0001; atrial fibrillation (AF) 7.64 (1.02, 57.13), p=0.006; LA clot 61.94 (8.28, 463.08$)$, $\mathrm{p}<0.0001$; giant LA > $65 \mathrm{~mm} 7.87$ (2.62, 23.56), $\mathrm{p}<0.0001$; poor left ventricular (LV) function $0.94(0.92,0.97), \mathrm{p}<0.0001$; and prolonged aortic clamp time $1.07(1.04,1.11), \mathrm{p}<0.0001)$. Propensity matching did not exhibit any difference in reoperations between bioprostheses and mechanical prostheses $(18.8 \%$ vs $13.3 \%, \mathrm{SMD}=-0.152, \mathrm{p}=0.1)$. At a median follow-up of 136 (IQR: 76-197) months, actuarial survival was $90.32 \% \pm 0.02 \%(\mathrm{p}=0.09)$ and there was no difference between the groups ( $\mathrm{p}=0.09)$.

Conclusions: Bioprostheses are an acceptable alternative to mechanical prostheses in young rheumatics aged <45 years unwilling for mechanical valve, redo surgeries, life-long anticoagulation, and those desirous of pregnancy.

Key words: bioprostheses; cerebral haemorrhage; mechanical prostheses; mitral valve replacement; propensity score matching; thromboembolism

Running title: Mitral bioprostheses in young rheumatics

\section{Introduction}

Each year, more than 20,000 mitral valve operations are reported to STS database. [1] Despite the increased emphasis on valve repair, at least $30 \%$ of patients still undergo MVR. [1-4]

Current consensus guidelines of the AHA and ESC, uniformly recommend either type of prosthetic valve for patients aged 60 to 70 years and mechanical prosthesis for patients $<60$ years. [5-7] These recommendations are based on the results of 4 randomized controlled trials that demonstrated no significant difference in late survival. [6-9] Two of these trials compared mechanical and bioprosthetic valve models implanted in 1970s and 1980s. [8-10] The other 2 trials included patients undergoing aortic valve replacement. [4-6] Contemporary data are limited to small single center studies. [11-13]

Valve replacement in young adults entails a choice between a mechanical prosthesis with risks of anticoagulation-related bleeding/thrombosis versus bioprosthesis necessitating eventual reoperation. The reported incidence of survival following mechanical MVR in the published 
literature at 10,20 and 30 years is $61-75 \%, 36.5-39 \%$, and $22.6 \%$ respectively. $[2-4,12]$ Over the last 20 years, there is a shift away from a clear cut age limit towards patients' wish and lifestyle considerations. $[6,11,12]$ This may be related to the enhanced durability of newgeneration bioprostheses, improved outcomes of redo surgery, or development of transcatheter valve-in-valve implantation. [6,11]

Although investigators have evaluated survival and valve-related complications, little information is available regarding composites of complications, namely valve-related reoperations, morbidity, and mortality in young rheumatics. [12,13] In 2018, we published our preliminary observations on the result of MVR using Carpentier-Edwards PERIMOUNT bioprosthesis in young rheumatics aged <40 years. [14]

The primary objective of this study was to compare the very late-term (20 years) outcomes of composites of valve-related complications in young rheumatics aged $<45$ years, undergoing bioprosthetic or mechanical MVR. The secondary objectives were to: i) compare the short- and longterm hemodynamic performance of prosthesis and SVD of bioprostheses, and ii) ascertain the duration and intensity of anticoagulation required in bioprosthetic group in immediate and late postoperative period and before re-replacement of degenerated bioprostheses.

\section{Materials and Methods}

This retrospective study conforms to the principles outlined in the declaration of Helsinki and was approved by the Institutional Ethics Committee.

\section{Patient selection criteria}

Choice of prosthesis for MVR was determined by patients' preference and surgeon's judgement based on patients' age and comorbidities, bleeding risk, life-style, and compliance to anticoagulation. Young rheumatics aged <45 years undergoing isolated MVR using either mechanical (St. Jude Medical or ATS Medical) or bioprosthesis (St. Jude Epic or Carpentier-Edwards PERIMOUNT) with or without tricuspid annuloplasty were included in this descriptive case series.

Patients undergoing MVR using prosthesis other than mentioned above, non-rheumatic etiology, and concomitant cardiac surgery were excluded. Young females desirous of pregnancy, patients coming from remote rural areas making follow-up and anticoagulant monitoring practically difficult, contraindications to use of anticoagulation, thrombosed mechanical mitral prosthesis, and patients' choice were indications for bioprosthetic MVR.

In patients with mitral stenosis and a small left ventricle, the low-profile Epic bioprosthesis was chosen over PERIMOUNT prosthesis. There were no specific criteria for selection of mechanical prosthesis.

We retrospectively reviewed medical records of young rheumatics aged $<45$ years who underwent either a bioprosthetic (Group I) or mechanical (Group II) MVR from January 1998 to December 2019 by the corresponding author.

A total of 600 mitral mechanical prostheses (SJM Mechanical, $n=300$; ATS Medical, $\mathrm{n}=300$ ) and 295 bioprostheses (Carpentier-Edwards PERIMOUNT model 6900 (Edwards Lifesciences, Baxter Healthcare Corporation, Irvine, CA, USA, $\mathrm{n}=165$; St. Jude Epic Porcine bioprosthesis, $\mathrm{n}=130$ ) were implanted. Among these, 132 patients of PERIMOUNT were from our previous investigation, and 33 were new patients in Group I (Figure 1). [14]

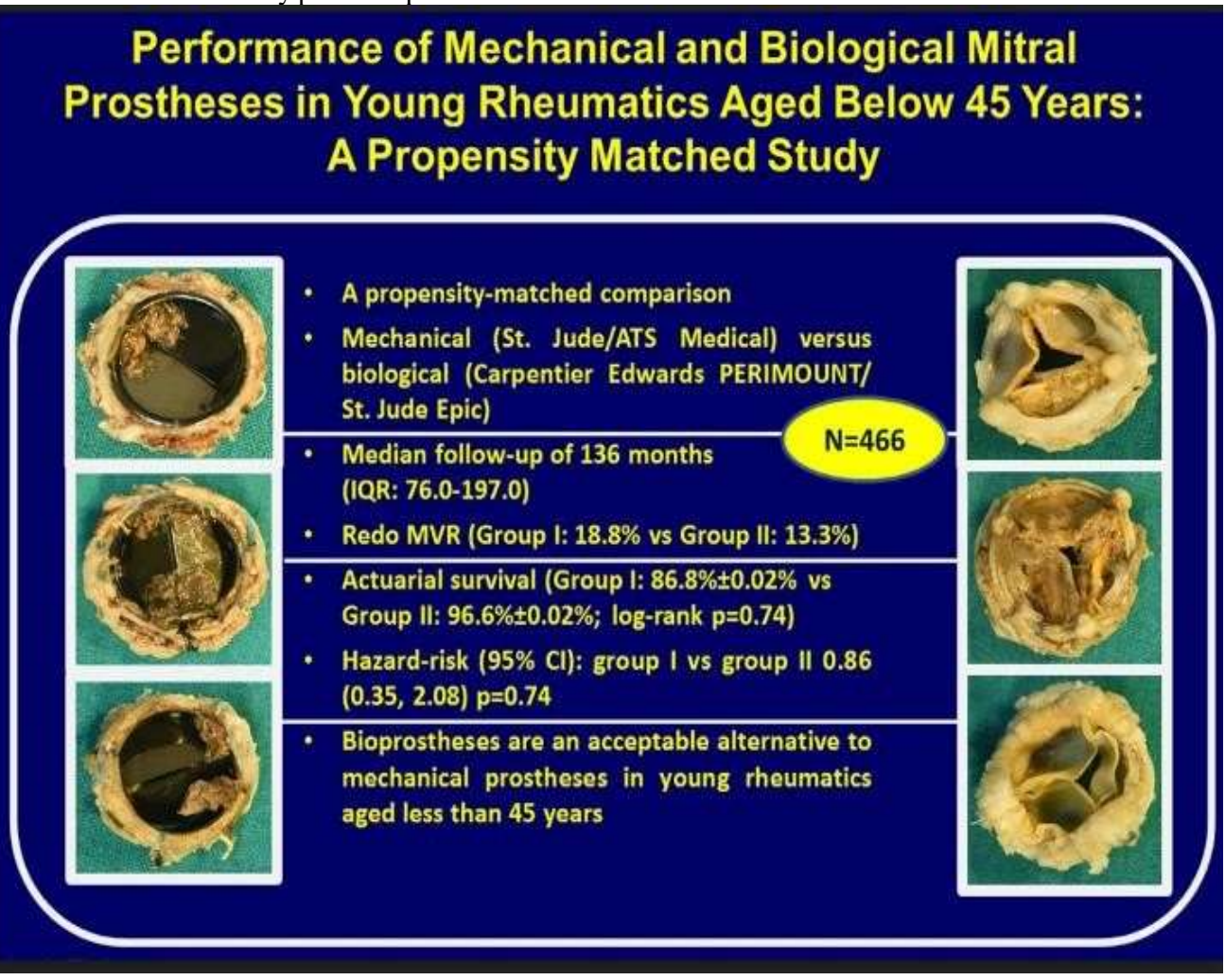

Figure 1: Graphic display ( $\mathrm{n}=466$ ) showing long-term valve-related actuarial survival of Group I and Group II patients.

Patients were matched one-to-one according to age, sex, preoperative thromboembolism, presence of atrial fibrillation (AF), advanced NYHA status, preoperative CHF requiring inotropes and ventilation, LVEF $<0.25$, size of LA $>65 \mathrm{~mm}$, and presence of LA clot according to optimal match technique. A power calculation estimated that approximately 233 patients per group were required to have a minimum of $80 \%$ power to detect a $10 \%$ difference in mortality between the 2 groups with a 2 -sided $\alpha$ of 0.05 Table 1, Figures 2A, 2B). 


\begin{tabular}{|c|c|c|c|c|c|c|c|c|}
\hline \multirow[b]{2}{*}{ Covariates } & \multicolumn{4}{|c|}{ Before Propensity Score Matching } & \multicolumn{4}{|c|}{ After Propensity Score Matching } \\
\hline & $\begin{array}{l}\text { Bioprosthetic } \\
\text { MVR } \\
\text { (Group I, } \\
\text { n=295) } \\
\text { No. of patients } \\
(\%) \\
\end{array}$ & $\begin{array}{c}\text { Mechanical } \\
\text { MVR (Group } \\
\text { II, n=600) } \\
\text { No. of patients } \\
(\%)\end{array}$ & $S M D$ & p-value & $\begin{array}{l}\text { Bioprosthetic MVR } \\
\text { (Group I, } n=233 \text { ) } \\
\text { No. of patients (\%) }\end{array}$ & $\begin{array}{c}\text { Mechanical } \\
\text { MVR (Group } \\
\text { II, n=233) } \\
\text { No. of patients } \\
\quad(\%)\end{array}$ & $S M D$ & p-value \\
\hline $\begin{array}{ll}\text { Sex } & \\
- & \text { Male } \\
- & \text { Female } \\
\end{array}$ & $\begin{array}{l}105(35.6 \%) \\
190(64.4 \%)\end{array}$ & $\begin{array}{l}242(40.3 \%) \\
358(59.7 \%)\end{array}$ & -0.126 & 0.259 & $\begin{array}{c}84(36.1 \%) \\
149(63.9 \%)\end{array}$ & $\begin{array}{c}87(37.3 \%) \\
146(62.7 \%)\end{array}$ & -0.087 & 0.773 \\
\hline \begin{tabular}{cc}
\multicolumn{2}{l}{ Dyspnoea } \\
- $\quad$ Yes \\
$-\quad$ No
\end{tabular} & $\begin{array}{c}292(98.9 \%) \\
3(1.1 \%)\end{array}$ & $\begin{array}{c}570(95 \%) \\
30(5 \%)\end{array}$ & 0.235 & 0.003 & $\begin{array}{c}231(99.1 \%) \\
2(0.9 \%)\end{array}$ & $\begin{array}{c}230(98.7 \%) \\
3(1.3 \%)\end{array}$ & -0.042 & 1.00 \\
\hline $\begin{array}{l}\text { New York Heart } \\
\text { Association } \\
-\quad \text { Class IV } \\
-\quad \text { Class III }\end{array}$ & $\begin{array}{c}76(25.8 \%) \\
219(74.2 \%)\end{array}$ & $\begin{array}{l}168(28 \%) \\
432(72 \%)\end{array}$ & -0.052 & 0.480 & $\begin{array}{c}59(25.3 \%) \\
174(74.7 \%)\end{array}$ & $\begin{array}{c}66(28.3 \%) \\
167(71.7 \%)\end{array}$ & 0.068 & 0.464 \\
\hline $\begin{array}{c}\text { CCF on inotropes \& } \\
\text { ventilator } \\
-\quad \text { Present } \\
-\quad \text { Absent }\end{array}$ & $\begin{array}{c}46(15.6 \%) \\
249(84.4 \%)\end{array}$ & $\begin{array}{l}110(18.3 \%) \\
490(81.7 \%)\end{array}$ & -0.075 & 0.310 & $\begin{array}{c}41(17.6 \%) \\
192(82.4 \%)\end{array}$ & $\begin{array}{c}42(18 \%) \\
191(82 \%)\end{array}$ & 0.011 & 0.904 \\
\hline $\begin{array}{l}\text { Renal Failure requiring } \\
\text { peritoneal/ hemodialysis } \\
-\quad \text { Yes } \\
-\quad \text { No }\end{array}$ & $\begin{array}{c}12(4.1 \%) \\
283(95.9 \%)\end{array}$ & $\begin{array}{c}38(6.3 \%) \\
562(93.7 \%)\end{array}$ & -0.103 & 0.165 & $\begin{array}{c}13(5.6 \%) \\
220(94.4 \%)\end{array}$ & $\begin{array}{c}10(4.3 \%) \\
223(95.7 \%)\end{array}$ & -0.059 & 0.521 \\
\hline $\begin{array}{c}\text { Thromboembolism } \\
-\quad \text { Yes } \\
\text { - } \quad \text { No }\end{array}$ & $\begin{array}{c}26(8.8 \%) \\
269(91.2 \%)\end{array}$ & $\begin{array}{c}72(12 \%) \\
52888(\%)\end{array}$ & -0.106 & 0.151 & $\begin{array}{c}21(9 \%) \\
21291(\%)\end{array}$ & $\begin{array}{c}23(9.9 \%) \\
210(90.1 \%)\end{array}$ & 0.029 & 0.751 \\
\hline $\begin{array}{rr}\text { Atrial fibrillation } \\
- & \text { Present } \\
- & \text { Absent } \\
\end{array}$ & $\begin{array}{c}198(67.1 \%) \\
97(32.9 \%)\end{array}$ & $\begin{array}{l}402(67 \%) \\
198(33 \%)\end{array}$ & 0.005 & 0.972 & $\begin{array}{c}166(71.2 \%) \\
67(28.7 \%)\end{array}$ & $\begin{array}{c}165(70.8 \%) \\
68(29.2 \%)\end{array}$ & -0.009 & 0.919 \\
\hline \begin{tabular}{cc}
\multicolumn{2}{l}{ Left atrial clot } \\
- & Present \\
- & Absent \\
\end{tabular} & $\begin{array}{c}68(23.1 \%) \\
227(76.9 \%)\end{array}$ & $\begin{array}{l}154(25.7 \%) \\
446(74.3 \%)\end{array}$ & -0.063 & 0.394 & $\begin{array}{c}57(24.5 \%) \\
176(75.5 \%)\end{array}$ & $\begin{array}{c}53(22.7 \%) \\
180(77.3 \%)\end{array}$ & -0.040 & 0.663 \\
\hline \begin{tabular}{cc}
\multicolumn{2}{l}{ Previous operation } \\
$-\quad$ Yes \\
$-\quad$ No
\end{tabular} & $\begin{array}{c}85(28.8 \%) \\
210(71.2 \%)\end{array}$ & $\begin{array}{l}256(42.6 \%) \\
344(57.4 \%)\end{array}$ & -0.295 & $<0.001$ & $\begin{array}{c}73(31.3 \%) \\
160(68.7 \%)\end{array}$ & $\begin{array}{c}68(29.2 \%) \\
16570.8(\%)\end{array}$ & -0.047 & 0.614 \\
\hline $\begin{array}{cc}\text { Mitral valve pathology } \\
- & \text { MS } \\
- & \text { MS+MR }\end{array}$ & $\begin{array}{c}202(68.5 \%) \\
93(31.5 \%)\end{array}$ & $\begin{array}{l}370(62 \%) \\
228(38 \%)\end{array}$ & 0.139 & 0.053 & $\begin{array}{c}167(71.7 \%) \\
66(28.3 \%)\end{array}$ & $\begin{array}{c}167(71.7 \%) \\
66(28.3 \%)\end{array}$ & $<0.001$ & 1.00 \\
\hline $\begin{array}{c}\text { Left atrial size }>65(\mathrm{~mm}) \\
-\quad \text { Yes } \\
-\quad \text { No }\end{array}$ & $\begin{array}{l}112(37.9 \%) \\
183(62.1 \%)\end{array}$ & $\begin{array}{l}260(43.3 \%) \\
340(56.7 \%)\end{array}$ & -0.112 & 0.165 & $\begin{array}{c}75(32.2 \%) \\
158(67.8 \%)\end{array}$ & $\begin{array}{c}80(34.3 \%) \\
153(65.7 \%)\end{array}$ & 0.045 & 0.623 \\
\hline $\begin{array}{l}\text { Surgical left atrial } \\
\text { reduction } \\
-\quad \text { Yes } \\
-\quad \text { No }\end{array}$ & $\begin{array}{l}109(36.9 \%) \\
186(63.1 \%)\end{array}$ & $\begin{array}{l}240(40 \%) \\
360(60 \%)\end{array}$ & -0.065 & 0.0 .379 & $\begin{array}{c}70(30 \%) \\
163(70 \%)\end{array}$ & $\begin{array}{c}77(33 \%) \\
156(67 \%)\end{array}$ & 0.065 & 0.485 \\
\hline $\begin{array}{cc}\text { Chordal preservation } \\
- & \text { Yes } \\
- & \text { No } \\
\end{array}$ & $\begin{array}{c}202(68.5 \%) \\
93(31.5 \%)\end{array}$ & $\begin{array}{l}420(70 \%) \\
180(30 \%)\end{array}$ & -0.031 & 0.641 & $\begin{array}{c}56(24 \%) \\
177(76 \%) \\
\end{array}$ & $\begin{array}{c}63(27 \%) \\
17073(\%) \\
\end{array}$ & -0.069 & 0.457 \\
\hline $\begin{array}{l}\text { Left atrial appendage } \\
\text { ligation } \\
-\quad \text { Yes } \\
-\quad \text { No } \\
\end{array}$ & $\begin{array}{c}262(88.8 \%) \\
33(11.2 \%)\end{array}$ & $\begin{array}{c}520(86.7 \%) \\
80(13.3 \%)\end{array}$ & 0.057 & 0.363 & $\begin{array}{c}212(90.9 \%) \\
21(9.1 \%)\end{array}$ & $\begin{array}{c}208(89.3 \%) \\
25(10.7 \%)\end{array}$ & -0.057 & 0.534 \\
\hline \begin{tabular}{cc}
\multicolumn{2}{l}{ Reoperation } \\
$-\quad$ Yes \\
$-\quad$ No
\end{tabular} & $\begin{array}{c}45(15.2 \%) \\
250(84.8 \%)\end{array}$ & $\begin{array}{c}58(9.7 \%) \\
542(90.3 \%)\end{array}$ & -0.027 & 0.717 & $\begin{array}{c}44(18.8 \%) \\
189(81.2 \%)\end{array}$ & $\begin{array}{c}31(13.3 \%) \\
202(86.7 \%)\end{array}$ & -0.152 & 0.101 \\
\hline \begin{tabular}{cc}
\multicolumn{2}{l}{ Cumulative events } \\
- & Yes \\
- & No \\
\end{tabular} & $\begin{array}{c}45(15.2 \%) \\
250(84.8 \%)\end{array}$ & $\begin{array}{l}114(19 \%) \\
486(81 \%) \\
\end{array}$ & -0.101 & 0.168 & $\begin{array}{c}58(24.9 \%) \\
175(75.1 \%)\end{array}$ & $\begin{array}{c}44(18.8 \%) \\
189(81.2 \%)\end{array}$ & -0.145 & 0.117 \\
\hline \begin{tabular}{cc}
\multicolumn{3}{l}{ Cumulative mortality } \\
$-\quad$ Yes \\
$-\quad$ No
\end{tabular} & $\begin{array}{c}10(\% 3.4) \\
285(96.6 \%)\end{array}$ & $\begin{array}{c}42(7 \%) \\
558(93 \%)\end{array}$ & -0.163 & 0.030 & $\begin{array}{c}10(4.3 \%) \\
223(95.7 \%)\end{array}$ & $\begin{array}{c}21(9.1 \%) \\
212(90.9 \%)\end{array}$ & -0.042 & 0.648 \\
\hline
\end{tabular}




\begin{tabular}{|c|c|c|c|c|c|c|c|c|}
\hline \multirow[b]{2}{*}{ Covariates } & \multicolumn{4}{|c|}{ Before Propensity Score Matching } & \multicolumn{4}{|c|}{ After Propensity Score Matching } \\
\hline & $\begin{array}{l}\text { Bioprosthetic } \\
\text { MVR } \\
\text { (Group I, } \\
\text { n=295) } \\
\text { No. of patients } \\
(\%) \\
\end{array}$ & $\begin{array}{c}\text { Mechanical } \\
\text { MVR (Group } \\
\text { II, n=600) } \\
\text { No. of patients } \\
(\%) \\
\end{array}$ & $S M D$ & $p$-value & $\begin{array}{l}\text { Bioprosthetic MVR } \\
\text { (Group I, } n=233 \text { ) } \\
\text { No. of patients }(\%)\end{array}$ & $\begin{array}{c}\text { Mechanical } \\
\text { MVR (Group } \\
\text { II, n=233) } \\
\text { No. of patients } \\
(\%)\end{array}$ & $S M D$ & $p$-value \\
\hline $\begin{array}{l}\text { Age (years) } \\
\quad(\text { Mean } \pm \text { SD) }\end{array}$ & $33.56 \pm 7.71$ & $32.80 \pm 8.36$ & 0.098 & 0.186 & $32.82 \pm 8.08$ & $33.52 \pm 7.70$ & 0.089 & 0.34 \\
\hline $\begin{array}{c}\text { Body weight }(\mathrm{kg}) \\
\text { (Mean } \pm \mathrm{SD})\end{array}$ & $49.36 \pm 11.30$ & $49.07 \pm 8.13$ & 0.028 & 0.662 & $48.45 \pm 6.91$ & $49.20 \pm 11.22$ & 0.081 & 0.385 \\
\hline $\begin{array}{l}\begin{array}{l}\text { Preoperative left } \\
\text { ventricular ejection } \\
\text { fraction }(\%) \\
\text { (Mean } \pm \text { SD) }\end{array} \\
\end{array}$ & $49.27 \pm 20.09$ & $43.60 \pm 18.6$ & 0.301 & $<0.0001$ & $48.90 \pm 16.92$ & $48.64 \pm 20.04$ & -0.014 & 0.882 \\
\hline $\begin{array}{l}\text { Aortic cross clamp time } \\
\text { (minutes) } \\
(\text { Mean } \pm \mathrm{SD})\end{array}$ & $41.32 \pm 14.55$ & $36.20 \pm 11.66$ & 0.387 & $<0.0001$ & $42.47 \pm 14.76$ & $40.20 \pm 14.35$ & -0.156 & 0.093 \\
\hline $\begin{array}{l}\text { Cardiopulmonary } \\
\text { bypass time (minutes) } \\
(\text { Mean } \pm \text { SD) }\end{array}$ & $56.26 \pm 15.21$ & $51.57 \pm 13.66$ & 0.324 & $<0.0001$ & $57.21 \pm 17.38$ & $55.44 \pm 15.11$ & -0.108 & 0.243 \\
\hline Follow-up (months) & $133.38 \pm 3.19$ & $138.18 \pm 3.07$ & & 0.329 & $135.91 \pm 74.04$ & $132.67 \pm 54.71$ & & 0.601 \\
\hline
\end{tabular}

Table 1: Preoperative and intraoperative characteristics of patients undergoing MVR before and after propensity score matching
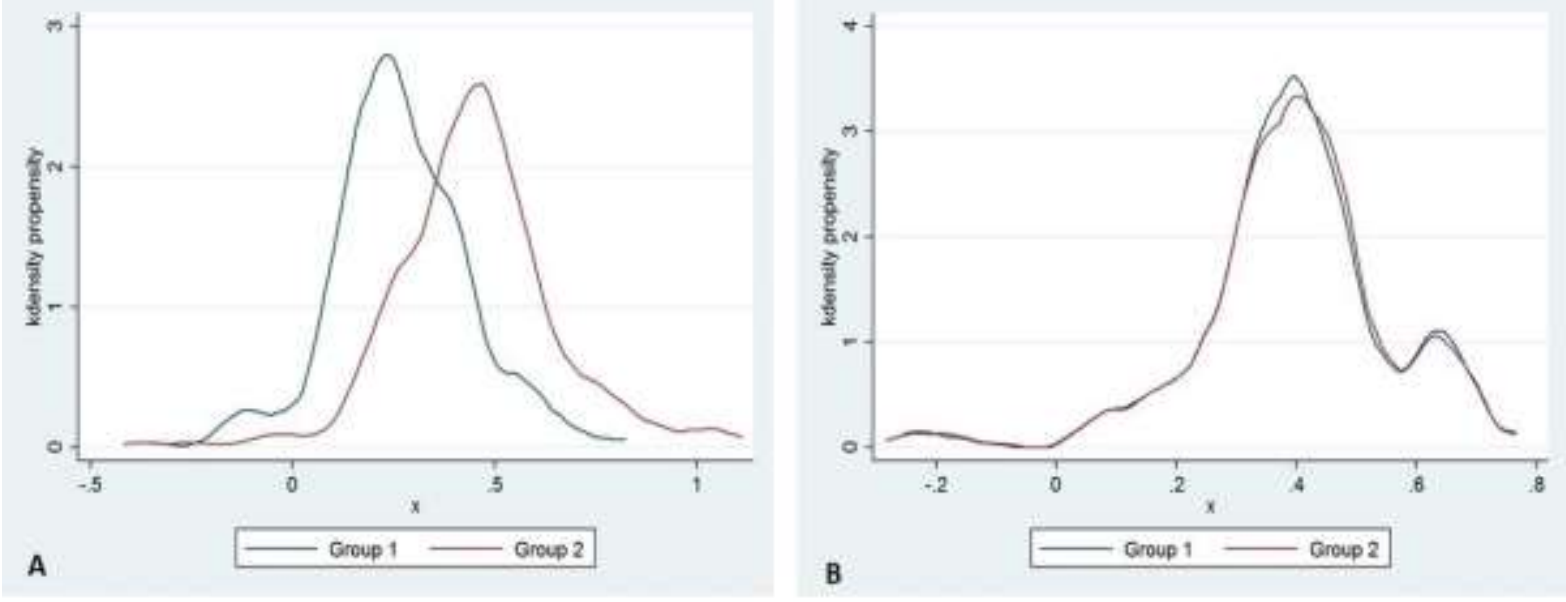

Figures 2A, 2B: Propensity density graph before (2A) and after (2B) propensity score matching.

Six-monthly follow-up data included clinical history, NYHA class assessment, and valve-related events. [15] If 6-monthly evaluation was not possible after repeated attempts to contact the patient, it was considered missing. If two consecutive evaluations were missing, the patient was considered lost to follow-up.

Transthoracic two-dimensional (2D), colour flow and Doppler echocardiography was performed within first six months and then annually. [16]

\section{Definitions}

\section{Outcome measures}

Valve-related mortality included death caused by thrombosis, thromboembolism, hemorrhage, SVD, non-structural dysfunction, or prosthetic valve endocarditis and death related to reoperation for a valverelated complication including sudden unexplained, unexpected deaths. Valve-related mortality was defined either as early/perioperative (i.e. in hospital or within 30 days of operation) or late (after 30 days) attributed to the explanted valve. $[17,18]$
Valve-related morbidity was defined as permanent valve-related impairment as a result of permanent neurologic or other functional deficits caused by valve thrombosis, thromboembolism, hemorrhage, structural valve deterioration, non-structural dysfunction, prosthetic valve endocarditis, or reoperation.

Late reoperations were defined as reoperations that occurred more than 30 days after implant. Reoperations were defined as any subsequent MVR. Reoperations that did not involve mitral valve replacement were excluded.

Structural valve deterioration was diagnosed as clinically relevant valvular stenosis or insufficiency by Doppler echocardiography, reoperation, or necropsy. Examples included cuspal perforation, tear, thickening, calcification, stiffness, stretching, wear and abrasions, thinning, leaflet escape, stent creep, or stress fracture. Structural deterioration that resulted from endocarditis, paravalvular leak, or thrombosis was not included in the structural valve deterioration category.

Stroke was defined as any cerebrovascular accident documented during the index hospitalization as well as any subsequent hospital admission in 
which the principal diagnosis was hemorrhagic or ischemic stroke (not including transient ischemic attacks).

A major bleeding event was defined as any subsequent hospital admission in which the principal diagnosis was intracerebral hemorrhage, hemopericardium/cardiac tamponade, gastrointestinal hemorrhage, hematuria, hemarthrosis, hemoptysis, or retinal hemorrhage. Bleeding events were classified as major (i.e. requiring hospital admission or transfusion, of intracranial location, or causing death), or minor (i.e. prospectively recorded but not major).

Heart failure was defined as per previous publications as the composite end-point of (i) New York Heart Association (NYHA) functional class 3 or 4 for more than 4 consecutive weeks, corroborated with physical examination, chest X-Ray, ECG and echocardiography findings when available, or (ii) death where the primary or main contributing diagnosis was heart failure.

\section{Anticoagulation}

Patients with bioprosthetic MVR were started on warfarin and aspirin (100mg/day) on first postoperative day maintaining an INR between 2.0 and 2.5. After discharge, patients were reviewed at one week, one month, three months, then subsequently at six months interval. Anticoagulation was stopped in patients with bioprosthetic MVR and normal sinus rhythm at 12 weeks of follow up.

Patients with a preoperative LA/LAA clot, history of recent thromboembolism, aneurysmal LA, AF, and degenerated bioprosthesis were maintained on anticoagulation with an INR between 1.5 and 1.8. All patients received aspirin life-long, unless contraindicated.
Patients undergoing mechanical MVR received life-long warfarin and aspirin (100mg/day) maintaining INR between 2.5 to 3.5 . The three study end-points were the composites of valve-related complications (mortality, morbidity and reoperations), explantation due to thrombosed mechanical prosthesis and SVD.

\section{Selection of a balanced cohort}

Table 1 shows the significant imbalances in baseline characteristics between patients treated with mechanical and biological mitral prostheses before matching. To assemble a balance cohort of patients with mechanical and biological mitral prostheses, we used propensity-score matching method on those with mechanical and biological mitral prostheses on measured baseline characteristics. For this purpose, we estimated propensity scores for treatment (group) for each of the 895 patients using multivariable logistic regression model. Group was used as the dependent variable and baseline characteristics namely- LA reduction, aortic cross-clamp time, thromboembolism, dyspnoea, previous operation, LVEF, chordal preservation, type of mitral valve disease were included as covariates to find the best optimal match set. Here, model's effectiveness are not important because propensity-score based models are sample-specific adjusters and are not intended to be used for out-ofsample prediction, discrimination or estimation of coefficients. The efficacy of propensity-score models is best assessed by estimating postmatch absolute standardized differences between baseline covariates that directly quantifies the bias in the means or proportions of covariates across the groups. Therefore, we presented before and after propensity match standardized differences and its findings in Love plots (Figure 3).

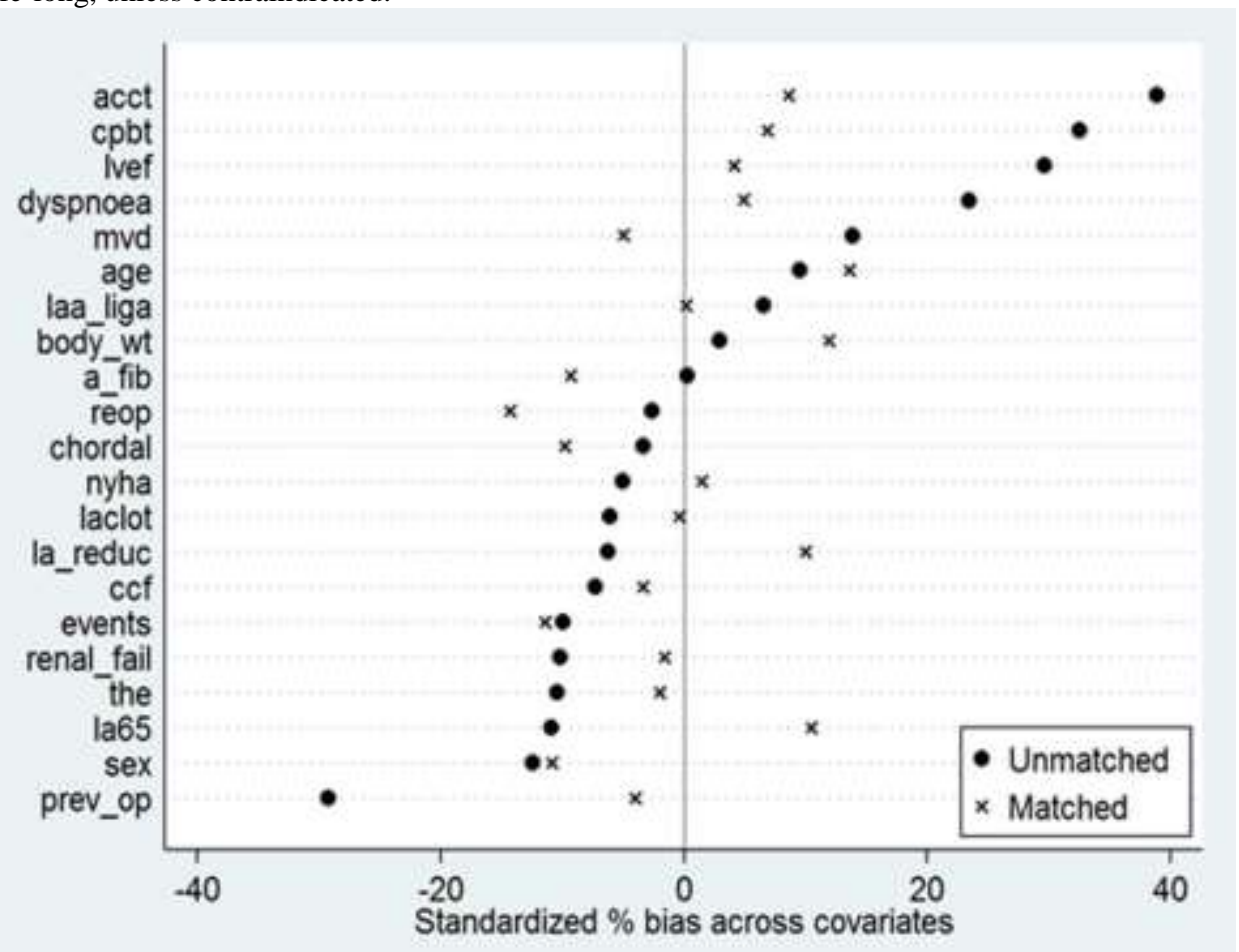

Figure 3: Love plot depicting standardized mean of difference (SMD) for covariates balancing before and after propensity score matching

An absolute standardized difference of $0 \%$ indicates no residual bias and, $15 \%$ is considered of inconsequential bias. Greedy nearest neighbouring matching method was used for matching protocol with a caliper of 0.1 to match 1: 1 patients with mechanical and biological mitral prostheses. We were able to match 233 of the 600 mechanical prostheses patients with 233 patients of biological mitral prostheses.

\section{Statistical Analysis}

For descriptive analyses, we used Pearson Chi-square/Fisher's exact test and t-test/Wilcoxon rank-sum tests for before match and McNemar's test and paired sample t-test/sign-rank test for after match comparisons of baseline covariates between patients with mechanical and biological 
mitral prostheses. Kaplan-Meier curve with $95 \%$ confidence interval and matched Cox regression analyses were used to determine the associations of group with various outcomes during months of follow-up. All statistical analyses were done using STATA 14.0 Software (College Station, Texas, USA) and two-sided tests with a p-value of $<0.05$ were considered statistically significant.

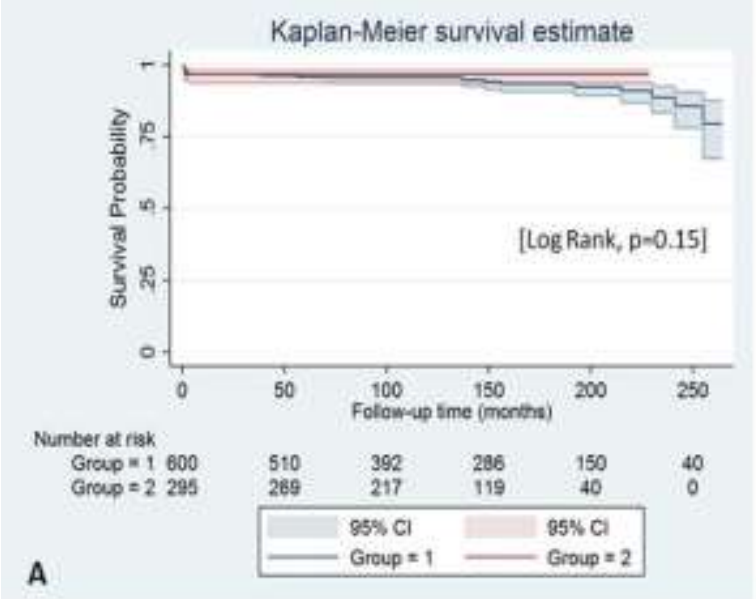

The freedom from the composites of valve-related complications (mortality, reoperation and adverse postoperative events) were calculated by Kaplan-Meier actuarial methods and compared with log-rank statistic (Figures 4A, 4B, 5A, 5B, 6A, 6B).

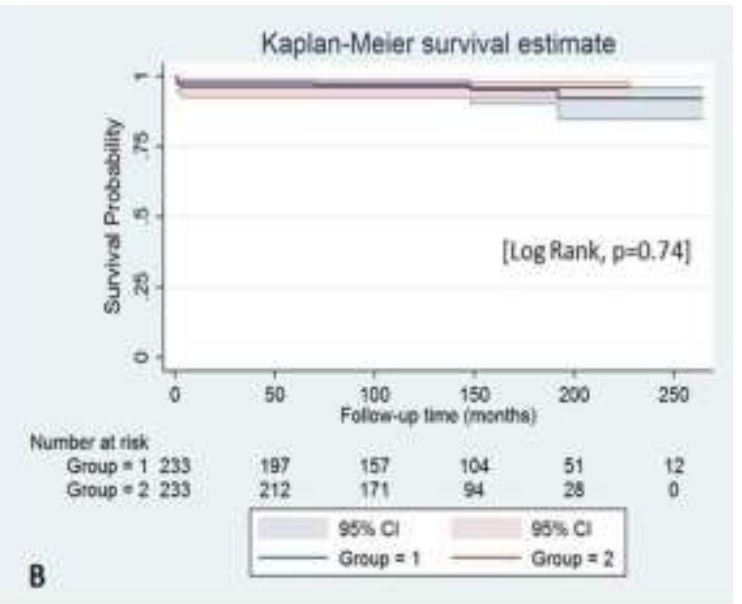

Figures 4A, 4B: Survival probability from Kaplan-Meier curve before (5A) and after (5B) propensity score matching (Log rank: group I vs group II, unmatched $p=0.15$; matched $p=0.74)$.
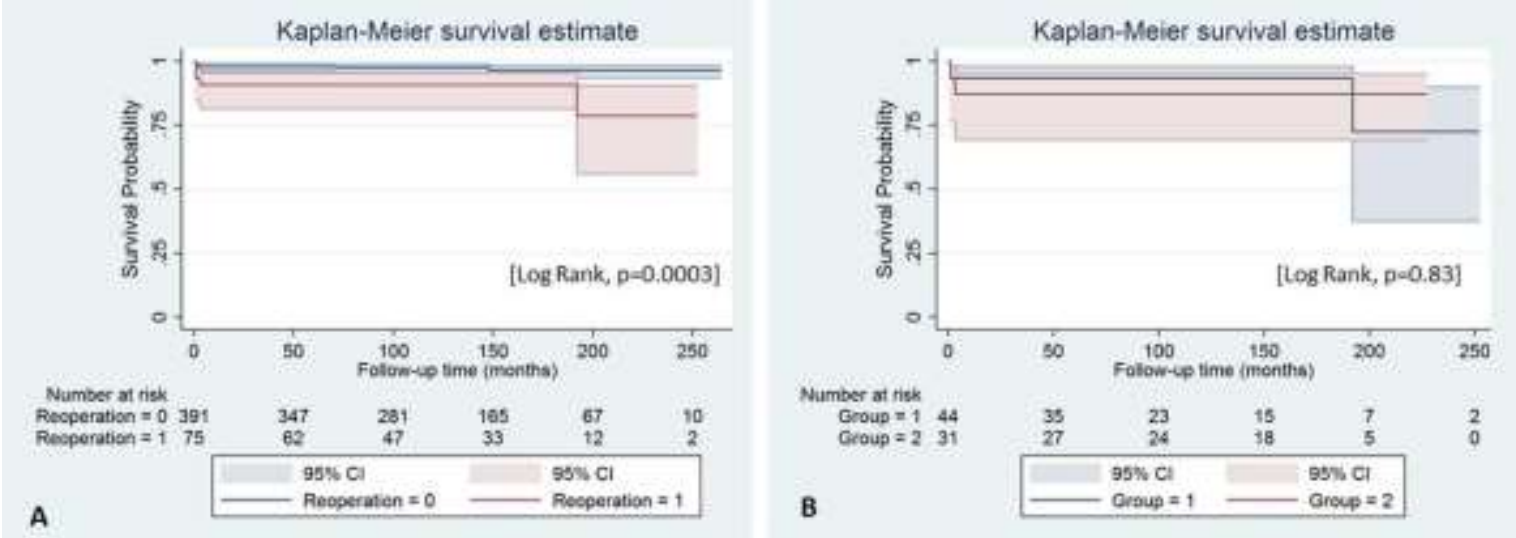

Figures 5A, 5B: Survival probability from Kaplan-Meier curve of patients undergoing reoperation. Figure 5A compares survival probability between reoperation vs no reoperation. Figure 5B depicts survival probability of patients undergoing reoperation between Group I and Group II
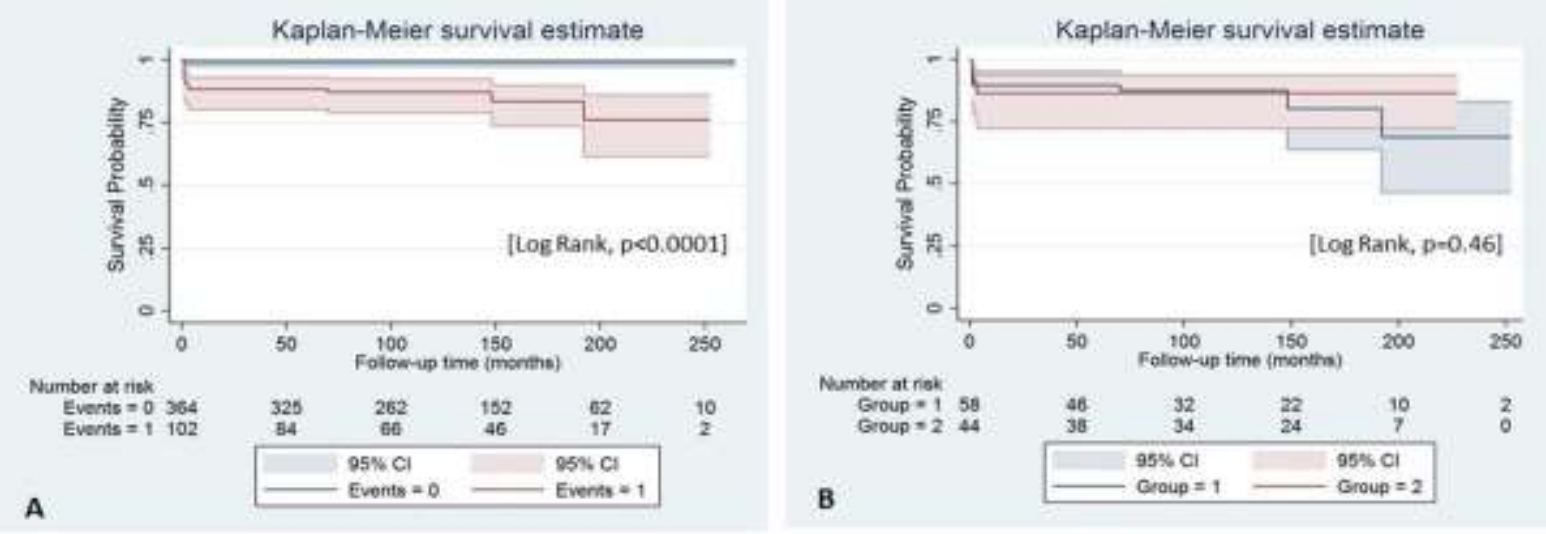

Figures 6A, 6B: Survival probability from Kaplan-Meier curve of patients with and without adverse postoperative events. Figure 6A compares survival probability with and without adverse events in the study group. Figure $6 B$ depicts survival probability of patients with and without adverse events between group I and group II. 


\section{Results}

\section{Study population}

After matching as described previously, our final study population consisted of a total of 466 patients aged between 12 and 45 (Group I: mean 32.82 \pm 8.08 , median 33.0 (IQR: 27-40) years; Group II: mean 33.52 \pm 7.7 , median 34.0 (IQR: 28-39) years (SMD 0.08, $\mathrm{p}=0.34$ ).

As presented in Table 1, after propensity matching, there were no differences among the 233 matched pairs in preoperative characteristics and both groups were fairly homogenous. Our institutional policy is to use bioprostheses beyond 18-years of age after bone growth and maturation are completed. In this study, one patient aged 12-years with a thrombosed mechanical prosthesis and another patient aged 13-year with thalassemia and hemolysis underwent bioprosthetic MVR.

\section{Surgical techniques}

The technical details of the surgical steps have been enumerated in the video presentation (Video Presentation) as well as in our earlier publication. $[3,4]$ Every attempt was made to preserve the chordopapillary apparatus ensuring implantation of an appropriate sized prosthesis without leaflet entrapment or LVOTO.

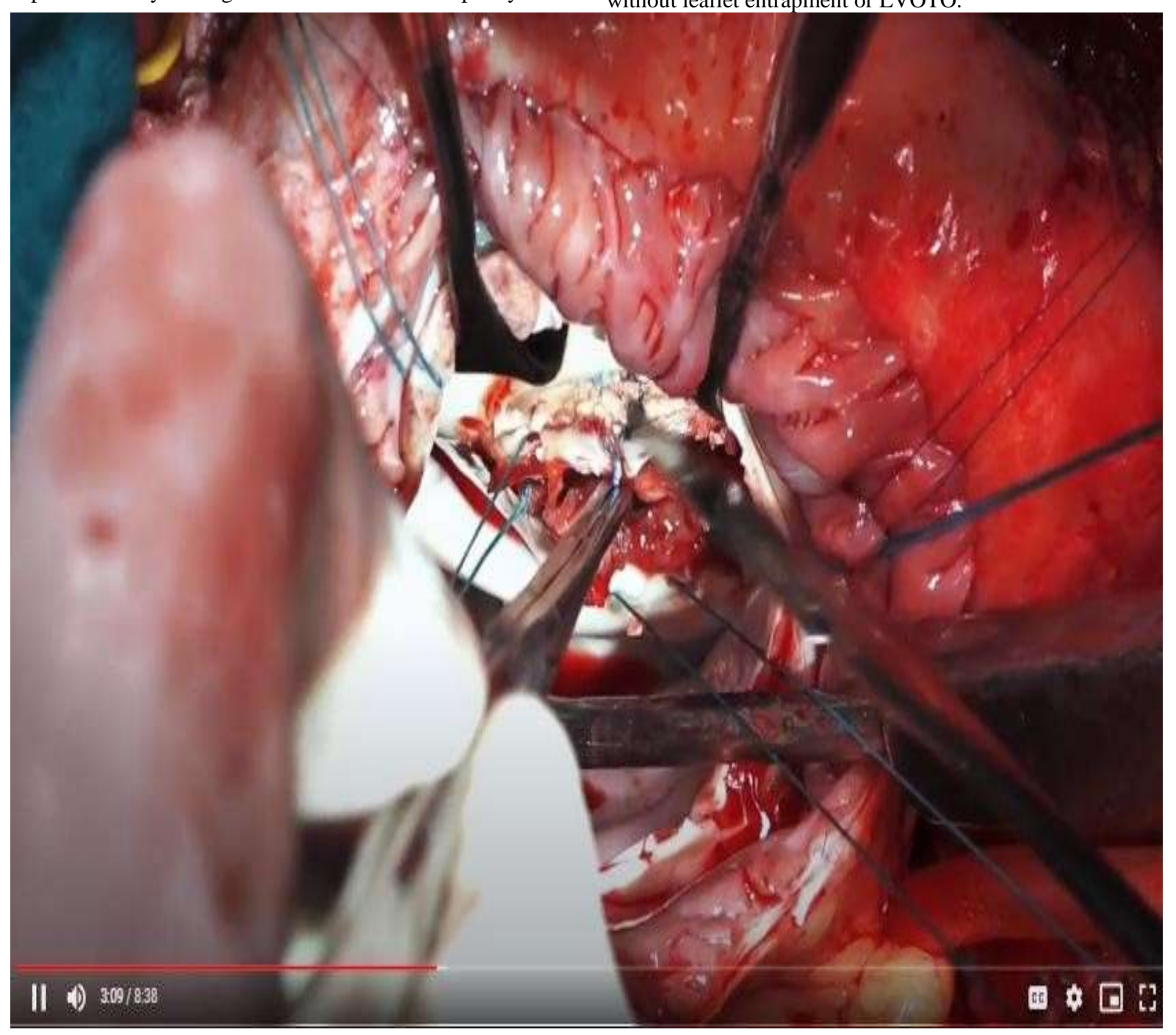

In patients with predominantly stenotic lesions with severe chordopapillary fusion, MVR was performed without chordal preservation. [3,4] Intraoperative transoesophageal echocardiography was performed to confirm satisfactory prosthetic valve function immediately after surgery.
Patients undergoing redo MVR $(n=75)$ were subjected to a uniform surgical protocol standardised by the corresponding author. A mechanical heart valve [(Medtronic Open PivotTM AP $360^{\circ}$ Apex and AP, Medtronic Inc., Mx, USA); size 24mm ( $\mathrm{n}=17), 26 \mathrm{~mm}(\mathrm{n}=19)$; St. Jude Medical Inc. St. Paul, Minn, 27mm $(\mathrm{n}=21), 29 \mathrm{~mm}(\mathrm{n}=18)]$ was used in patients undergoing explantation for SVD (Video presentation), (Figure 7A-7D). 
A
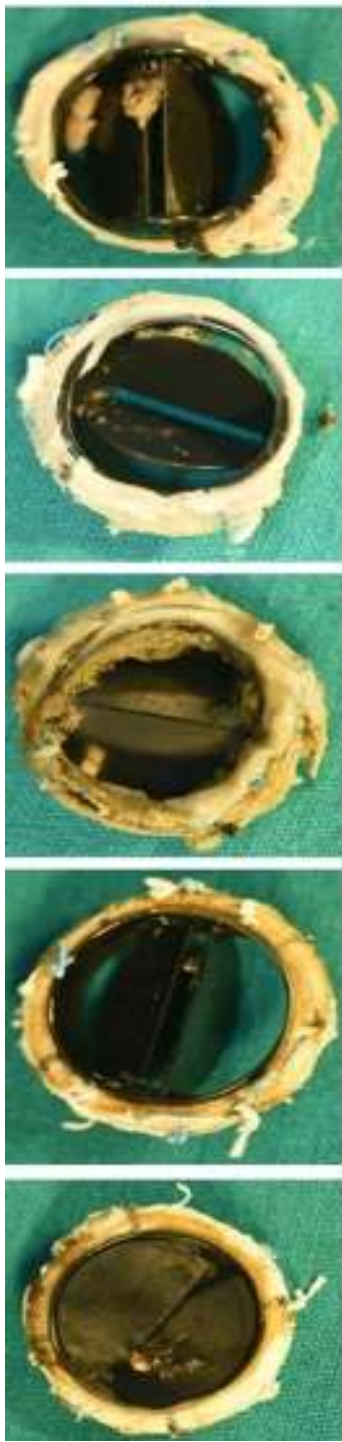

B
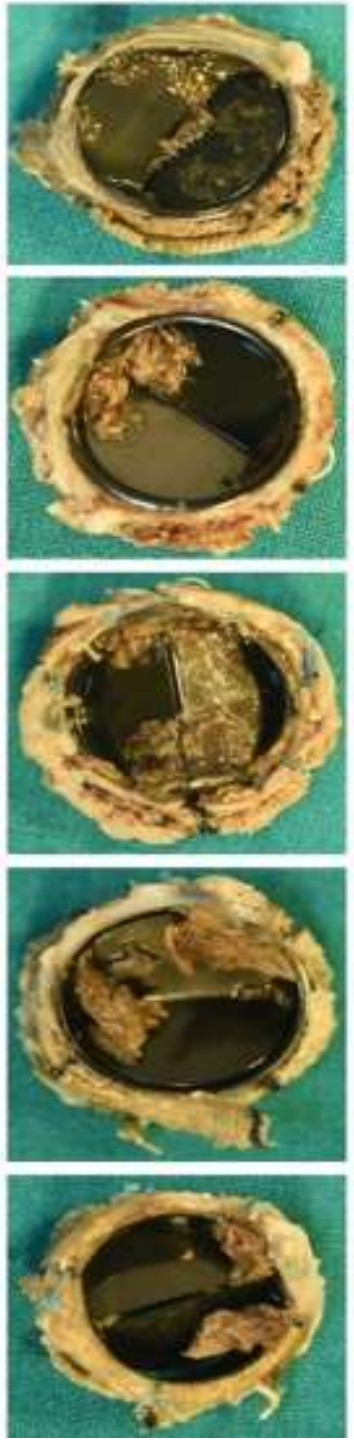

C
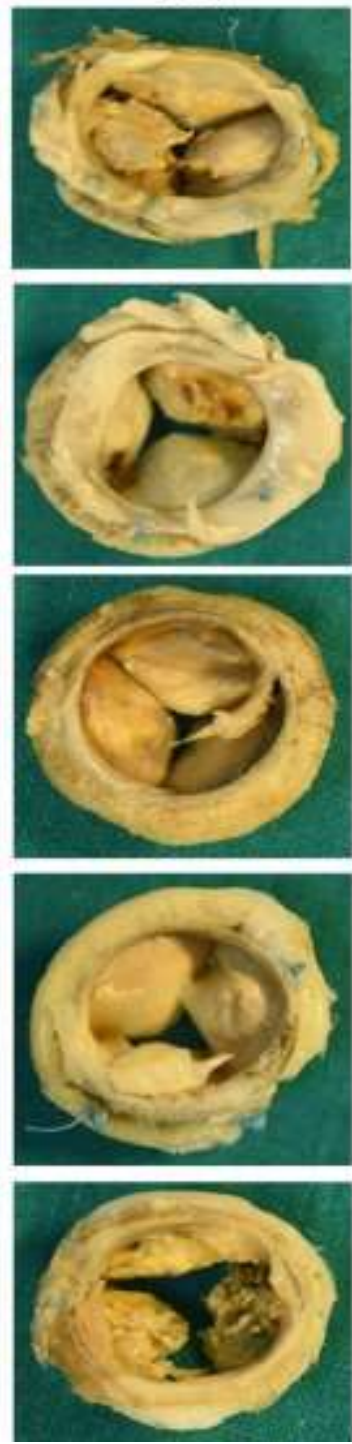

D
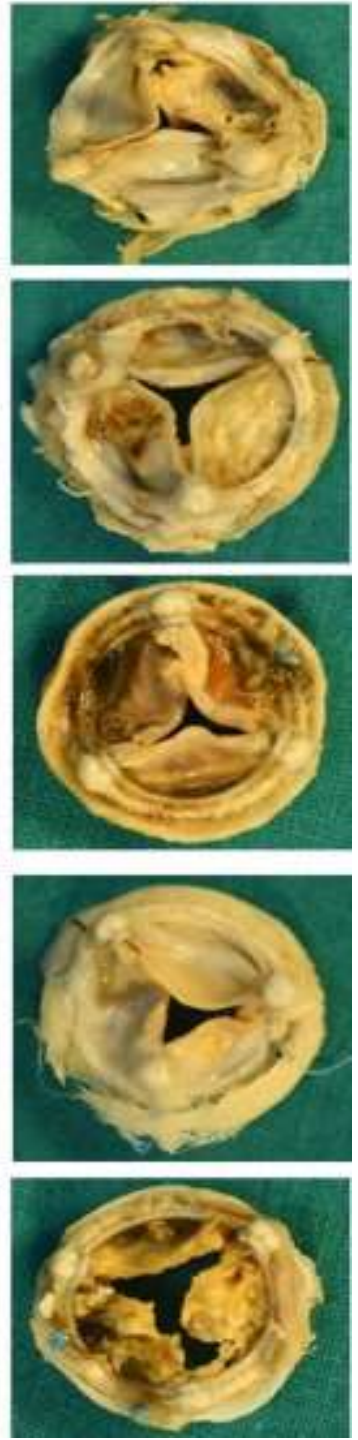

Figure 7A-7D: Photographs of explanted St. Jude mechanical valve with thrombotic occlusion of leaflets (A, B) and PERIMOUNT bioprostheses (C, D) showing structural valve deterioration (Cuspal perforation, tear, thickening, calcification, stiffness, wear and abrasions, creep, and stress fracture).

Median ischemic time for group I patients was 37 minutes (IQR: 31-50); and for group II was 35 minutes (IQR: $30-50),(\mathrm{SMD}=-0.15, \mathrm{p}=0.09)$. Median CPB time for group I was 49 minutes (IQR: 46-69); and for group II was 49 minutes (IQR: 43-69), ( $\mathrm{SMD}=-0.1, \mathrm{p}=0.2)$ respectively. One hundred and forty-seven (31.5\%) patients underwent LA reduction for giant LA. No surgery was performed for AF (Table 1).

\section{Operative mortality and morbidity}

\begin{tabular}{|l|c|c|c|}
\hline Covariates & $\begin{array}{c}\text { Bioprosthetic MVR } \\
\text { (Group I, n=233) } \\
\text { No. of patients (\%) }\end{array}$ & $\begin{array}{c}\text { Mechanical MVR (Group II, } \\
\text { n=233) } \\
\text { No. of patients (\%) }\end{array}$ & $\begin{array}{c}\text { p value } \\
8(3.4 \%)\end{array}$ \\
\hline Mortality & $5(2.1 \%)$ & $7(3.0 \%)$ & 0.40 \\
\hline Reoperation for bleeding & $8(3.4 \%)$ & $9(3.9 \%)$ & 0.79 \\
\hline Tracheostomy ventilator support & $7(3.0 \%)$ & $11(4.7 \%)$ & 0.61 \\
\hline Pericardiocentesis & $8(3.4 \%)$ & $3(1.3 \%)$ & 0.48 \\
\hline Transient ischemic attack & $2(0.8 \%)$ & 0.65 & \\
\hline
\end{tabular}

Table 2A: Early complications (within 30 days)
There were $5(2.1 \%)$ hospital deaths in group I and $8(3.4 \%)$ in group II due to LCOS after reoperation for thrombosed mechanical prosthesis $(n=4) /$ failed mitral valve reconstruction $(n=5)$, intractable ventricular arrhythmias $(n=2)$ and sepsis $(n=2)$ with left ventricular and renal failure. Comparative assessment of early complications between the two groups revealed no differences in incidence of perioperative mortality and morbidities (Table 2A).

Table 2A: Early complications (within 30 days)




\section{Late outcomes}

Late mortality was $2.1 \%(n=5)$ in group I and $5.6 \%(n=13)$ in group II $(\mathrm{p}=0.05)$. The causes were persistent $\mathrm{CHF}(\mathrm{n}=12)$, intractable ventricular arrhythmias $(n=5)$, and renal failure $(n=1)$ between 45 days and 215 months following surgery. A combination of persistent CHF, intractable ventricular arrhythmias and renal failure were the causes of death of 12 patients undergoing redo MVR (Group I; $n=7$ : Group II; $n=5$ ). The other causes were anticoagulant-related massive intracerebral hemorrhage $(n=4)$, and sepsis $(n=2)$, (Table 2B).

\begin{tabular}{|c|c|c|c|}
\hline Covariates & $\begin{array}{c}\text { Bioprosthetic MVR } \\
\text { (Group I, n=233) } \\
\text { No. of patients }(\%)\end{array}$ & $\begin{array}{c}\text { Mechanical MVR (Group II, } \\
\text { n=233) } \\
\text { No. of patients }(\%)\end{array}$ & p value \\
\hline Death & $6(2.1 \%)$ & $13(5.6 \%)$ & 0.05 \\
\hline Atrial fibrillation & $145(62.2 \%)$ & $166(71.2 \%)$ & 0.19 \\
\hline Thromboembolic events & $4(1.7 \%)$ & $15(6.4 \%)$ & 0.01 \\
\hline Reoperation & $44(18.8 \%)$ & $31(13.3 \%)$ & 0.89 \\
\hline Bleeding requiring hospitalization & Nil & $4(1.7 \%)$ & 0.04 \\
\hline New York Heart Association II & $18(7.7 \%)$ & $13(5.6 \%)$ & 0.35 \\
\hline
\end{tabular}

Table 2B: Outcomes at late follow-up (beyond 30 days)

On hazard regression analysis, the risk of cumulative mortality was equal in both groups [HR 0.86 (95\% CI 0.35, 2.08), p=0.73] (Table 3).

Thromboembolic complications occurred in 19 patients (Group I: $n=4$; Group II: $n=15)$ : transient ischemic attack (TIA) $(n=12)$, dysarthria $(n=4)$, and hemiplegia $(n=3)$. Two patients in Group I developed prosthetic valve endocarditis and were managed conservatively.

Although cumulative mortality was more in mechanical arm (Group I: $4.5 \%$ vs Group II: $9.9 \%$; $\mathrm{SMD}=-0.04, \mathrm{p}=0.64)$, there was no difference in actuarial survival between two groups (Group I: $86.8 \%+/ 0.02 \%$ vs Group II: $96.6 \% \pm 0.02$ (log-rank: unmatched $\mathrm{p}=0.15$, matched $\mathrm{p}=0.74$ ), (Figures 4A, 4B).

Requirement for redo MVR was similar between the two propensity matched groups $(\mathrm{SMD}=-0.15, \mathrm{p}=0.1)$. Patients undergoing reoperation were associated with 4.38 (95\% CI 1.81, 10.57) times increased risk of death compared to non-reoperated group $(\mathrm{p}=0.002)$ and there was significantly decreased probability of long-term survival (log rank $\mathrm{p}=0.0003$ ) (Table 3, Figures 5A, 5B). At a median follow up of 136 months (IQR: $76.0-197.0), 18.8 \%(n=44)$ of group I, and $13.3 \%(n=31)$ of group II patients underwent redo MVR using mechanical prosthesis, and there was no difference in actuarial survival between the two groups ( $\log$ rank $\mathrm{p}=0.83$ ) (Figure 5B). Valve leaflet thickening with mild prosthetic valve stenosis (Epic $n=6$, PERIMOUNT $n=2$ ) was seen between 84 and 100 months of follow-up and being closely followed-up.

The composites of valve-related cumulative events were similar between the two propensity matched groups [Group I: $24.8 \%(n=58)$ vs Group II $18.8 \%(\mathrm{n}=44),(\mathrm{SMD}=-0.14, \mathrm{p}=0.1)$. The actuarial event free survival at a median follow-up of 136 months was $99.6 \% \pm 0.01 \%$ (Group I) vs $98.4 \% \pm 0.01 \%$ (Group II: $\log$ rank $\mathrm{p}=0.15$ ), (Figures 6A, 6B). Hemorrhagic complications necessitating hospitalisation occurred in 4 (1.7\%) patients in group II. Four (1.7\%) patients of group I and $15(6.4 \%)$ patients of group II experienced thromboembolic complications. The linearized valve-related adverse postoperative cumulative events were 1.37 events/100 patient-years for group II and 1.38 events/100 patientyears $(\mathrm{p}=0.89)$ for group I. At late follow-up, more patients were in $\mathrm{AF}$ in mechanical arm (Group I: 62.2\% vs Group II: 71.2\%, p=0.19) (Table 2B).

Eight patients were lost to follow-up. Four hundred and twenty-seven (98.2\%) patients were followed-up ranging from 1 month to 264 months (Group I: median 142.5, IQR: 75.5-199.5; Group II: median 134, IQR 99179 months). The total follow-up was 4839.3 patient-years data (median 136, IQR: 76-197 months). Out of 427 patients, $402(94.1 \%)$ were in NYHA class I and $25(5.7 \%)$ were in NYHA class II. The actuarial survival at a median follow-up of 136 (IQR: 76-197) months was $90.32 \% \pm 0.02 \%(95 \% \mathrm{CI}: 84.7-93.9)$ with no difference between two groups (Log rank $\mathrm{p}=0.74)$, (Figures 4A, 4B).
The hazard regression model of risk factors for cumulative mortality included preoperative CHF on inotropes and ventilator $(\mathrm{p}<0.0001)$, renal failure requiring peritoneal/hemodialysis $(\mathrm{p}<0.0001)$, preoperative thromboembolism $(\mathrm{p}=0.001)$, preoperative $\mathrm{AF}(\mathrm{p}=0.006)$, presence of LA/LAA clot $(\mathrm{p}<0.0001)$, previous operation $(\mathrm{p}<0.0001)$, giant LA $(\mathrm{p}<0.0001)$, surgical LA reduction $(\mathrm{p}<0.0001)$, nil chordal preservation $(\mathrm{p}<0.0001)$, reoperation for SVD or thrombosed mechanical prostheses $(\mathrm{p}=0.002)$, adverse postoperative cumulative events $(\mathrm{p}<0.0001)$, poor LV function $(\mathrm{p}<0.0001)$, prolonged aortic clamp time $(\mathrm{p}<0.0001)$ and prolonged CPB time $(\mathrm{p}<0.0001)$. Propensity score matching did not exhibit any difference in reoperation between two groups (Group I vs Group II: $18.8 \%$ vs $13.3 \%, \mathrm{SMD}=-0.152$, p=0.1), (Table 2A, Table 3).

\section{Discussion}

Comparative data on late (15 years) and very late-term (20 years) performances of bioprostheses and mechanical prostheses in young rheumatics are limited and conflicting. [1-4,13,14,17-20]

The important findings of this retrospective study were:

i) Propensity score matching, and multivariable modeling minimized the biases and demonstrated similar long-term survival upto 22-years, in both group of patients,

ii) Composites of valve-related mortality, morbidity, defined as per neurologic and functional impairment favored bioprosthesis,

iii) Both groups exhibited similar valve - related reoperation rates (18.8\% vs $13.3 \%, \mathrm{SMD}=-0.15, \mathrm{p}=0.1)$, and

iv) Bioprosthetic arm exhibited lesser cumulative mortality [4.5\% $(\mathrm{n}=10)$ vs $9.9 \%(\mathrm{n}=21), \mathrm{SMD}=-0.04, \mathrm{p}=0.65]$ and was not statistically significant (HR $0.86,95 \%$ CI: $0.35,2.08, \mathrm{p}=0.74$ ) (Table 1, Table 3).

According to American College of Cardiology/American Heart Association 2006 guidelines:

\section{Class I:}

A bioprosthesis is indicated for MVR in patients who cannot take warfarin (Level of Evidence: C). [1]

\section{Class IIa:}

1. A mechanical mitral prosthesis is reasonable in patients aged $<65$ years with long-standing atrial fibrillation. (Level of Evidence: C)

2. A mitral bioprosthesis is reasonable in patients aged $>65$ years. (Level of Evidence: C) 
3. A mitral bioprosthesis is reasonable in patients aged $<65$ years in sinus rhythm who elect to receive this valve for lifestyle considerations. (Level of Evidence: C)

Published data indicate that strong consideration should be given to choosing a tissue over a mechanical prosthesis in patients aged $>60$ years, but the issue remains largely unsettled in patients aged $<60$ years. Randomised trials comparing biological and mechanical prosthesis in younger patients are scanty. [1-4,13,14,17-20]

Although, these studies have helped define the recommendations for prosthesis selection according to patient's age, they compared valve models implanted in 1970s and 1980s, had a considerable proportion of redo-thoracotomy/sternotomy patients at initial valve implantation, and reported perioperative mortalities at initial operation and at reoperation that were high $(>14 \%)$ by modern standards, thus potentially biasing against use of bioprosthesis. [1,8,19]

Thirdly, data with sufficient follow-up duration to adequately capture tissue prosthesis, reoperations, and long-term mortality in younger patients is lacking. Fourthly, a rapid development is witnessed in the field of bioprosthesis, with newly introduced devices every year. The production of some of the devices was even stopped before the long-term results were obtainable which indeed is mandatory for every new device.

The rationale for these studies is based on improved durability of bioprostheses, anticipated low risk of reoperation, and avoidance of longterm anticoagulation. Data on long-term survival of patients with bioprostheses, however, are conflicting. [1-4,13,14,17-20]

In developing countries, the severity and rapid progression of rheumatic valvular disease in pediatric and younger patients precludes repair in the great majority. Young patients face a difficult choice between a life time of anticoagulation and 1-3\% per year bleeding risk with mechanical prosthesis and a significant risk of reoperation due to SVD with bioprosthesis. [1-4,16,21-30] Whether reoperation is more hazardous than strokes and hemorrhage, long-term mortality may be the most important criterion for comparison and literature is divided on the recommendation in young rheumatics. [17-21]

In this study, actuarial survival of bioprosthesis was $96.6 \% \pm 0.02 \%$ and mechanical arm was $86.8 \% \pm 0.02 \%$ (log rank $\mathrm{p}=0.74$ ), (Figure 5A, 5B) which was statistically insignificant and in accordance with the published investigations of 10 -years survival of $52.3 \%$ with PERIMOUNT, $42 \%$ $58.8 \%$ with Epic and 60-70\% mechanical MVR.

Although direct comparisons across many studies may be misleading, it is reasonable to review the data as a whole and make generalizable statement in favour or disfavour of a particular prosthesis.

Survival analysis on 575 patients at 15 years by Hammermeister and colleagues showed lower all-cause mortality with mechanical AVR but not MVR. Bioprostheses were associated with significantly lower bleeding rates but higher rates of SVD. [9]

The Edinburgh trial studied 530 patients receiving either a Bjork-Shiley tilting disc valve or porcine bioprosthesis and concluded that mechanical prostheses had improved survival over bioprostheses at 12 years, but not at 20 years. Mechanical prostheses were associated with higher bleeding rate for both AVR and MVR. [2-4,8]

Beyond these randomized trials, the consensus is that bioprosthesis are associated with increased SVD and reoperation but lower bleeding and thromboembolism rates. [1-4,14,17-20] Several investigators have demonstrated conflicting data on valve-related reoperations between biologic and mechanical prostheses and mortality. [1-4,14,17-20]

Despite the divergence of data, at a median follow-up of 136 months (IQR:79-197), our reoperation rate was $18.8 \%$ for bioprosthesis and
$13.3 \%$ in mechanical arm, while reoperation for SVD was associated with 0.27 times lower risk of cumulative mortality than reoperation for thrombosed mechanical prosthesis $(\mathrm{p}<0.001)$.

This study is one of the largest to compare bioprosthetic and mechanical MVR with a median follow-up of 11.3 years. Our study doesn't include multiple biologic or mechanical valve models and therefore provides a pure comparison of most commonly used prostheses. The study inferred that bioprostheses appeared to be favourable based on lower incidence of valve-related morbidity. Since, no significant difference in re-operation was observed between prostheses, bioprostheses appear to be the clear preference for young rheumatics; offering an improved morbidity profile, without sacrificing durability.

\section{Study Limitations}

Although it is a retrospective study, our statistical methods attempt to control for most of the bias in assignment of valve type. Randomized controlled trials themselves are limited because randomization requires stratification on many prognostic variables and thus often leads to selection of very specific groups of patients with results that lack generalizability. In addition, randomization is based on few variables that the investigators consider as most significant predictors of outcome. In contrast, propensity score analysis provides a balance of two compared groups with weighted effects of the covariates on treatment variable and thus minimizing the bias related to imbalances in assignment of treatment type.

Secondly, like other observational cohorts, our results may not be generalizable to all young adults undergoing MVR in other centers.

\section{Conclusions}

This study adds equipoise to the notion of valve choice in young rheumatics aged <45 years. Bioprostheses are valid alternative to mechanical prostheses in patients from remote rural areas, those desirous of pregnancy, patients with bleeding risk, and those with thrombosed mechanical prostheses. Bioprostheses were undifferentiated in terms of composites of valve-related reoperation and mortality.

Survival from reoperation in bioprosthetic arm was superior to mechanical arm because of planned elective intervention, mostly when the patients were in functional class I/II. In light of this data, we conclude that choice of prosthesis for MVR should be based on patient's preference, ability to take anticoagulation, and the likelihood of reoperation.

\section{Conflict of interest: Nil}

\section{Source of funding: Nil}

\section{References}

1. Bonow RO, Carabello BA, Chatterjee K, et al. ACC/AHA 2006 Guidelines for management of patients with valvular heart disease: A report of the ACC/AHA Task Force on Practice Guidelines. J Am Coll Cardiol. 2006;48: e1-148.

2. John S, Ravikumar E, Jairaj PS, Chowdhury UK, et al. Valve replacement in young patient with rheumatic heart disease. Review of twenty-year experience. J Thorac Cardiovasc Surg 1990;99(4):631-638.

3. Chowdhury UK, Kumar AS, Airan B, et al. Mitral valve replacement with and without chordal preservation in rheumatic population: serial echocardiographic assessment of left ventricular size and function. Ann Thorac Surg 2005;79:1926- 1933.

4. Chowdhury UK, Venkataiya JKH, Patel CD, et al. Serial radionuclide angiographic assessment of left ventricular ejection fraction and regional wall motion after mitral valve replacement 
in patients with rheumatic disease. Am Heart J 2006;152: 12011207.

5. Nishimura RA, Otto CM, Bonow RO, et al. AHA/ACC guidelines for management of patients with valvular heart disease: A report of the ACC/AHA Task Force on Practice Guidelines. Circulation 2014; 129: 521-643.

6. Nakano K, Hirahara N, Motomura N, et al. Current status of cardiovascular surgery in Japan, 2013 and 2014: A report based on the Japan Cardiovascular Surgery Database. 4. Valvular heart surgery. Gen Thorac Cardiovasc Surg 2017; 66: 13 - 18.

7. Vahanian A, Alfieri O, Andreotti F, et al. Guidelines on management of valvular heart disease. Eur Heart J 2012; 33: 2451296.

8. Oxenham H, Bloomfield P, Wheatley DJ, et al. Twenty-year comparison of Bjork-Shiley mechanical heart valve with porcine bioprostheses. Heart. 2003;89:715-721.

9. Hammermeister K, Sethi GK, Henderson WG, et al. Outcomes 15years after valve replacement with mechanical versus bioprosthetic valve: final report of the Veterans Affairs randomized trial. J Am Coll Cardiol. 2000;36:1152-1158.

10. Stassano $\mathrm{P}$, Tommaso LD, Monaco $\mathrm{M}$, et al. A prospective randomized evaluation of mechanical versus biological valves in patients aged 55 to 70 years. J Am Coll Cardiol 2009;54:18621868.

11. Kaneko T, Cohn LH, Aranki SF. Tissue valve is the preferred option for patients aged 60 and older. Circulation 2013; 128: 1365 -1371 .

12. Rahimtoola SH. Choice of prosthetic heart valve in adults: an update. J Am Coll Cardiol. 2010;55:2413-2426.

13. Grunkemeier GL, Starr A, Rahimtoola SH. Clinical performance 22
Hurst's The Heart. New York, NY: McGraw-Hill, 1998:18511866.

14. Chowdhury UK, Rizvi A, Narang R, et al. Mitral valve replacement using Carpentier-Edwards pericardial bioprosthesis in patients with rheumatic heart disease aged <40 years: 17-year results. Heart Lung and Circulation 2018; 27: 864-871.

15. Edmunds LH Jr, Clark RE, Cohn LH, et al. Guidelines for reporting morbidity and mortality after cardiac valvular operations. Ann Thorac Surg 1988; 46: 257-259.

16. Cheitlin MD, Armstrong WF, Aurigemma GP, et al. ACC/AHA/ASE 2003 guideline update for the clinical application of echocardiography summary article: a report of the ACC/AHA Task Force on Practice Guidelines. J Am Coll Cardiol 2003;42:954 -970.

17. Ye-Ying C, Glower DD, Landolfo K, et al. Comparison of survival after mitral valve replacement with biologic and mechanical valves in 1139 patients. J Thorac Cardiovasc Surg 2001; 122: 569-577.

18. Jamieson WR, Lewis CT, Sakwa MP, et al. St Jude Medical Epic porcine bioprosthesis: results of regulatory evaluation. J Thorac Cardiovasc Surg. 2011;141: 1449-1454.e2.

19. Ruel M, Chan V, Be'dard P, et al. Very long-term survival implications of heart valve replacement with tissue versus mechanical prostheses in adults $<60$ years of age. Circulation. 2007;116(11 Suppl):I294-1300.

20. Kassai B, Gueyffier F, Cucherat M, Boissel JP. Comparison of bioprosthesis and mechanical valves, a meta-analysis of randomized clinical trials. Cardiovasc Surg. 2000;8:477-483.

21. Ikonomidis JS, Kratz JM, Crumbley AJ, et al. Twenty-year experience with St. Jude Medical mechanical valve prosthesis. J Thorac Cardiovasc Surg 2003; 6: 2022-2031.
This work is licensed under Creative Commons Attribution 4.0 License

\section{To Submit Your Article Click Here: Submit Manuscript}

DOI: $10.31579 / 2641-0419 / 149$

\footnotetext{
Ready to submit your research? Choose Auctores and benefit from:

* fast, convenient online submission

* rigorous peer review by experienced research in your field

* rapid publication on acceptance

* authors retain copyrights

* unique DOI for all articles

* immediate, unrestricted online access
}

At Auctores, research is always in progress.

Learn more www.auctoresonline.org/journals/clinical-cardiology-andcardiovascular-interventions 